Article

\title{
Microemulsion Encapsulated into Halloysite Nanotubes and their Applications for Cleaning of a Marble Surface
}

\author{
Giulia Lo Dico ${ }^{1}$, Francesca Semilia ${ }^{1}$, Stefana Milioto ${ }^{1}$, Filippo Parisi ${ }^{1}$ (I), \\ Giuseppe Cavallaro ${ }^{1}$ (i), Giuseppe Ingui ${ }^{2}$, Maziyar Makaremi ${ }^{3}{ }^{(0)}$, Pooria Pasbakhsh ${ }^{3}$ \\ and Giuseppe Lazzara $1, *$ (D) \\ 1 Dipartimento di Fisica e Chimica, Università degli Studi di Palermo, Viale delle Scienze pad 17, \\ 90128 Palermo, Italy; giulia.ldc@gmail.com (G.L.D.); molecolelibere@hotmail.it (F.S.); \\ stefana.milioto@unipa.it (S.M.); filippo.parisi@unipa.it (F.P.); giuseppe.cavallaro@unipa.it (G.C.) \\ 2 Restorer at Laurea Magistrale in Conservazione e Restauro per i Beni Culturali, Università degli Studi di \\ Palermo, Viale delle Scienze pad 17, 90128 Palermo, Italy; ingui.giuseppe@libero.it \\ 3 Advanced Engineering Platform, Mechanical Engineering Discipline, School of Engineering, \\ Monash University Malaysia, 47500 Selangor, Malaysia; mmak24@student.monash.edu (M.M.); \\ pooria.pasbakhsh@monash.edu (P.P.) \\ * Correspondence: giuseppe.lazzara@unipa.it; Tel.: +39-091-23897962
}

Received: 12 July 2018; Accepted: 15 August 2018; Published: 24 August 2018

Featured Application: Halloysite nanotubes for surface cleaning. Controlled cleaning of a marble surface.

\begin{abstract}
Halloysite nanotubes were used to incorporate anionic surfactant micelles and an organic solvent to generate a cleaning system to be applied in Cultural Heritage restoration. The targeted adsorption is driven by electrostatic interactions based on the nanotubes peculiar charge separation. Namely anionic species are driven to the positively charged inner surface while being prevented from interacting with the halloysite outer surface that possesses a positive charge density. The hybrid organic/inorganic emulsion was characterized by dynamic light scattering. Analysis of the autocorrelation function allowed us to define the presence of surfactant aggregates inside/outside the nanotube lumen as a function of the nanotube/surfactant ratio in an aqueous mixture. The application of this prepared emulsion for the controlled cleaning of a marble artifact is demonstrated. To this purpose, a membrane of nanofibrous polyacrylonitrile was prepared by electrospinning and was applied between the work of art and the cleaning agent to avoid the release of residues on the marble surface. This work represents a further step toward the opportunity to extend the use of emulsions for cleaning protocols for stone-based artifacts or in technological applications where surfactant separation is required by a simple centrifugation/sedimentation method.
\end{abstract}

Keywords: halloysite nanotubes; polyacrylonitrile; cultural heritages; surfactant

\section{Introduction}

Microemulsions have largely attracted attention in cleaning for Cultural Heritage restoration, replacing conventional methods that are difficult to control. In particular, the commonly used organic solvents or gels are often toxic and high evaporation rates can represent a risk for the operators. Moreover, the aggressive nature of the organic solvents may cause partial swelling and solubilization of the original artwork materials [1]. On the other hand, microemulsions allow for better control of diffusion at the surface of the substrate and their formulations require fewer amounts of solvents 
with a significant reduction in toxicity and environmental impact. Restoration of the Renaissance paintings by Masaccio, Masolino, and Lippi in the Brancacci Chapel in Florence (1984-1990) represents the first case study reporting the use of microemulsions for conservation purposes [2,3]. Recently, amphiphile-based systems were intensively studied by Piero Baglioni to remove synthetic materials (acrylic and vinyl polymers) from painted surfaces [4]. These results show that the designed nanostructures improved the traditional methods while both minimizing the environmental impact and the optimizing cleaning performance [4]. Disadvantages for the use of colloidal systems are related to the high wettability of the treated surface and to spreading within the substrate porosity. Small traces of surfactant that remain on the artwork may cause deterioration and, in some cases, lead to the complete disfiguration of painted surfaces [5]. A fascinating resolution is freezing the microemulsion dynamics into a rigid nanocontainer in such a way as to simplify the removal of the whole cleaning system [6].

Among nanomaterials, hybrid systems prepared by a combination of mesoporous particles and sustainable polymers or surfactants are promising for several applications within materials science and biotechnology [1,7-15]. Clay nanoparticles are promising as solid supports due to their sustainability and low cost [16-20]. Halloysite is an emerging hollow tubular clay which is naturally available worldwide and cheap compared to synthetic nanoparticles with similar morphology [16]. From a mineralogical viewpoint, halloysite is a 1:1 aluminosilicate $\left(\mathrm{Al}_{2} \mathrm{Si}_{2} \mathrm{O}_{5}(\mathrm{OH})_{4} \bullet 2 \mathrm{H}_{2} \mathrm{O}\right)$ that possesses two water molecules in the interlayer wall with a spacing of $10 \AA$ [21]. Similar to kaolinite, dehydrated halloysite presents a shorter interlayer wall periodicity $(7.2 \AA)$ due to the loss of the water molecules. Typically, halloysite nanotubes (HNTs) are quite polydisperse in nature depending on the geological deposit [22]. Biological studies conducted both in vitro and in vivo show that halloysite is a biocompatible and low toxic nanoparticle that can be employed for numerous medical and pharmaceutical purposes [23-28]. The hollow tubular shape and peculiar surface properties make HNTs suitable as catalytic supports for several reactions [29-34] as well as adsorbent systems for wastewater decontamination [35-38]. Filling polymeric matrices with halloysite presents as a successful strategy to obtain functional nanocomposite materials with excellent characteristics in terms of mechanical performance [39,40], thermal stability [10,41,42], and vapor barrier properties [43].

The unique behavior of HNTs allows for selective modification with functional molecules; promising for the preparation of organic/inorganic composites [44,45]. The opposite charges of the inside and outside surfaces allow for the selective adsorption of anionic or cationic surfactants presenting as an easy strategy to prepare new advanced hybrid materials [46,47]. Furthermore, it was demonstrated that the anionic surfactant modification of the internal surface increases the net negative charge of the nanotubes enhancing the electrostatic repulsions and consequently the dispersion stability [16]. Selective alkylphosphonic acid modification of HNTs are configured as inorganic micelle-like tubes with inner aliphatic chains and outer hydrophilic silicate shells [21]. The hydrophobic lumen allows encapsulation of neutral and hydrophobic molecules and the solid polar shell provides stability for nanotube dispersion in water while retaining encapsulated molecules [6]. These attractive systems are enabling different applications, such as water purification [48] and drug immobilization [46].

The obtained modified halloysite can be dispersed in a polymeric network giving rise to functional materials conformed as a film, exploited for bioactive packaging applications and for controlled release [49]. Recently, the co-dispersion of alginate and functionalized HNTs was performed as a new strategy, based on inorganic reverse micelles, for nanohydrogel formation which, is suitable for industrial and biological applications [46].

In this work, we prepared an oil in water emulsion using an anionic surfactant to target its adsorption into the HNT lumen. Dynamic light scattering experiments were carried out to characterize the aqueous mixture. Finally, an application in a real Cultural Heritage restoration is demonstrated. Electrospun nanofibrous membranes of polyacrylonitrile (PAN) were used to avoid direct contact with the work of art. It is reported that nanofibers of polyacrylonitrile can be used as efficient filters for 
halloysite nanoparticles in a quantitative way [50]. For the cleaning test, we selected an Egyptian Kilga, from Cairo, dating back to the 10th or 11th century, preserved today in the exhibition space dedicated to Islamic art at the Interdisciplinary Regional Gallery of Palazzo Abatellis. The Kilgas were probably born due to human need and survival, given the scarcity of fresh and pure water in the Nile Delta villages after a long period of drought and plague.

\section{Materials and Methods}

\subsection{Materials}

Halloysite nanotubes (HNTs) were obtained from Imerys Ceramics, scanning electron micrographs are provided in Supplementary Materials (Figure S2). Sodium dodecyl sulfate (SDS), tetradecane, 1-pentanol and polyacrylonitrile ( $\mathrm{PAN}, \mathrm{Mw}=150 \mathrm{kDa}$ ) were obtained from Sigma Aldrich (Milan, Italy). PAN membranes were prepared using an electrospinning method after PAN was dissolved in dimethyl sulfoxide (DMSO, purchased from Fisher Scientific) as a solvent and mixing for 12 hours. The PAN solution was electrospun onto a rotating drum (300 rpm) via an electrospinning device (NB-EN1, NanoBond, China), containing a metallic needle, a feed pump and a high voltage power supply. The sample was electrospun with a solution flow rate of $1.4 \mathrm{~mL} / \mathrm{h}$, at a distance of $15 \mathrm{~cm}$ and voltage of $13-14 \mathrm{kV}$. A detailed description of the preparation method has been explained in our previous study [50].

\subsection{Preparation of Oil in Water Emulsion}

An oil in water emulsion was prepared based on literature findings [51]. Briefly, water was mixed with tetradecane in different ratios. SDS and 1-pentanol, as co-surfactants, were added and the mixture was kept under magnetic stirring overnight. The investigated concentrations are provided in Table 1 , together with the tetradecane/SDS weight ratios $\left(\mathrm{R}_{\mathrm{oil} / \mathrm{SDS}}\right)$.

Table 1. Compositions of the investigated oil in water emulsions.

\begin{tabular}{ccccc}
\hline $\mathbf{R}_{\mathbf{o i} / \mathbf{S D S}}$ & SDS wt $\%$ & 1-Pentanol wt $\%$ & Tetradecane wt $\%$ & Water wt $\%$ \\
\hline 2.11 & 9 & 21 & 19 & 51 \\
2.12 & 8 & 30 & 17 & 45 \\
2.22 & 9 & 22 & 20 & 49 \\
2.25 & 8 & 31 & 18 & 43 \\
2.63 & 8 & 28 & 21 & 43 \\
2.75 & 8 & 27 & 22 & 43 \\
4.17 & 6 & 32 & 25 & 37 \\
\hline
\end{tabular}

\subsection{Preparation of Oil in Water Emulsion in the Presence of Halloysite}

The microemulsion with $\mathrm{R}_{\mathrm{oil} / \mathrm{SDS}}=2.63$ was used for incorporation into HNTs provided that the average size for the HNT lumen can be as small as $15 \mathrm{~nm}$ for our sample [52], based on the microemulsion size. Variable amounts of nanotubes have been explored in the range from 0.00125 to $0.043 \%$ in water.

The halloysite was added to the designed microemulsion without previous treatments, before incubation in an ultrasonic bath (5 minutes) to promote the loading of the micelles into the nanotubes.

The prepared inorganic micelle-like tubes were explored for $0.00016 \leq \mathrm{R}_{\mathrm{HNT} / \mathrm{SDS}} \leq 0.005$.

\subsection{Methods}

Dynamic light scattering (DLS) experiments were carried out using a Zetasizer NANO-ZS (Malvern Instruments, London, UK) at $25{ }^{\circ} \mathrm{C}$. The field-time autocorrelation functions were well 
described by a single or double exponential decay (Equation (1)), which provides the decay rate $(\Gamma)$ of each diffusive mode and its intensity weight.

$$
\mathrm{g}(\tau)=\mathrm{Be}^{\left(-2 \Gamma_{1}^{\tau}\right)}+\mathrm{Ce}^{\left(-2 \Gamma_{2}^{\tau}\right)}
$$

where $\mathrm{B}$ and $\mathrm{C}$ are pre-exponential factors, correlated to the concentration of the particles.

From the decay rates, we calculated the collective diffusion coefficients at a given concentration as $D_{t}=\Gamma / q^{2}$ where $q$ is the scattering vector given by $4 \pi n \lambda^{-1} \sin (\theta / 2)$ where $n$ is the water refractive index, $\lambda$ is the wavelength $(632.8 \mathrm{~nm})$ and $\theta$ is the scattering angle $\left(173^{\circ}\right)$. The apparent hydrodynamic radii ( $\mathrm{Rh}$ ) of the equivalent (with equivalent translational diffusion coefficients) spherical particles was calculated using the Stokes-Einstein equation as $R h=k_{b} T /(6 \pi \eta)$, where $k_{b}$ is the Boltzmann constant, $\mathrm{T}$ is the absolute temperature, and $\eta$ is the water viscosity.

From the pre-exponential factors, we calculated $B /(B+C)$ and $C /(B+C)$ as parameters providing the particle concentrations, proportional to a $\%$ of the two populations.

A microscope ESEM FEI QUANTA 200F (FEI Company, Cambridge, UK) was used to image the halloysite nanotubes, after gold coating in argon by means of an Sputter Coater S150A (EDWARDS, Burgess Hill, UK). Measurements were conducted in high vacuum $\left(<6 \times 10^{-4} \mathrm{~Pa}\right)$, at $15 \mathrm{kV}$ and a working distance of $10 \mathrm{~mm}$.

\section{Results}

\subsection{Oil in Water Emulsion}

The oil in water emulsions were characterized by DLS to identify the best conditions to prepare oil droplet sizes for loading into the HNT lumen. Figure 1 shows that all the hydrodynamic radii of the prepared suspensions were in the range of $4-22 \mathrm{~nm}$, suggesting the possibility of an efficient entrapment of the oil droplets into the nanotubes. The hydrodynamic volume (Figure 1) was calculated, assuming spherical-like micelles, and was reported as a function of $\mathrm{R}_{\mathrm{oil} / \mathrm{SDS}}$. We observed a linear increase in volume as the oil content increased, underlining the crucial role of oil in droplet size.

Furthermore, a first evaluation of the temporal stability of the prepared quaternary systems was carried out repeating the DLS measurement after 24 hours of storage at $25^{\circ} \mathrm{C}$. Retention of $99 \%$ of the initial size was obtained, showing the colloidal stability of the mixture.

The $\zeta$ potential for the microemulsions provided a negative value of $\sim-12 \mathrm{mV}$. These findings suggest the presence of a negative charge at the micelle/water interface, which guarantees the selective electrostatic interaction with HNT positive inner surface.

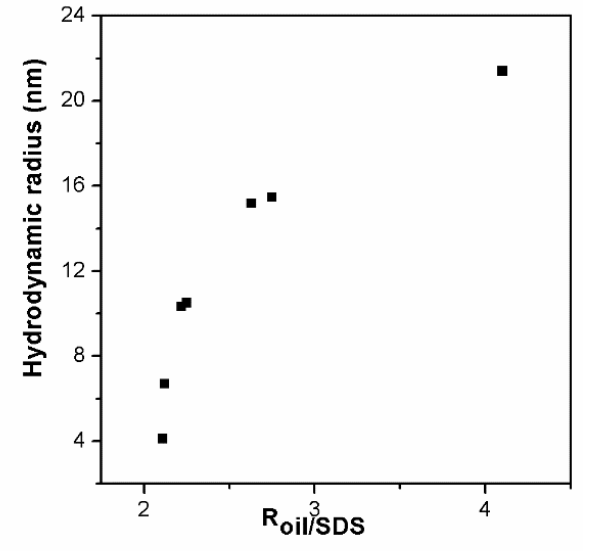

(a)

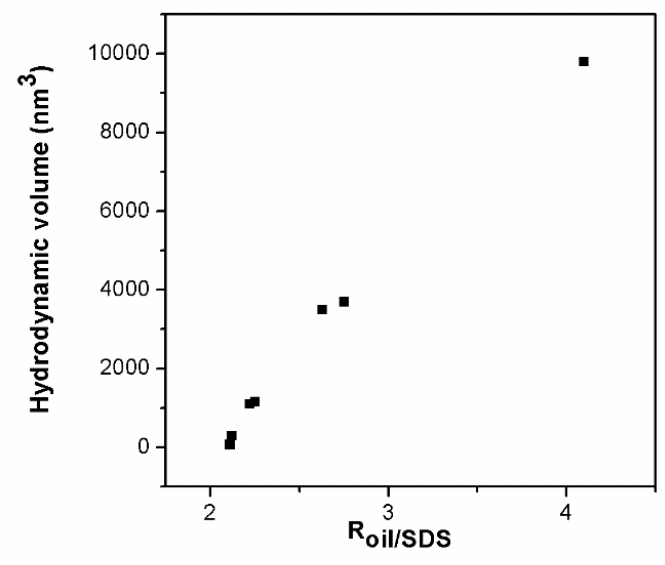

(b)

Figure 1. (a) Hydrodynamic radius; (b) Hydrodynamic volume of prepared microemulsions. 


\subsection{Oil in Water Emulsion in the Presence of HNT}

We explored the possibility of driving the oil droplet inclusion into the HNT lumen by electrostatic interactions. On this basis, an anion surfactant (SDS) was selected because it drives interactions with the positive charges of the HNT's inner surface.

Figure 2 displays the autocorrelation function, $g(\tau)$, obtained for the prepared suspensions with various HNT amounts in the microemulsion. A double exponential decay is observed and is correlated to the presence of two particle populations namely, oil in water droplets and HNTs. In particular, the initial decay is associated with fast particles (microemulsion) and as time progresses, the decay is associated with slow particles (HNTs). Typically, the particle volume is the parameter that most affects DLS behavior. We also observed an increase in $\mathrm{g}(\tau)$ intensity for the second decay as the HNT content increased.

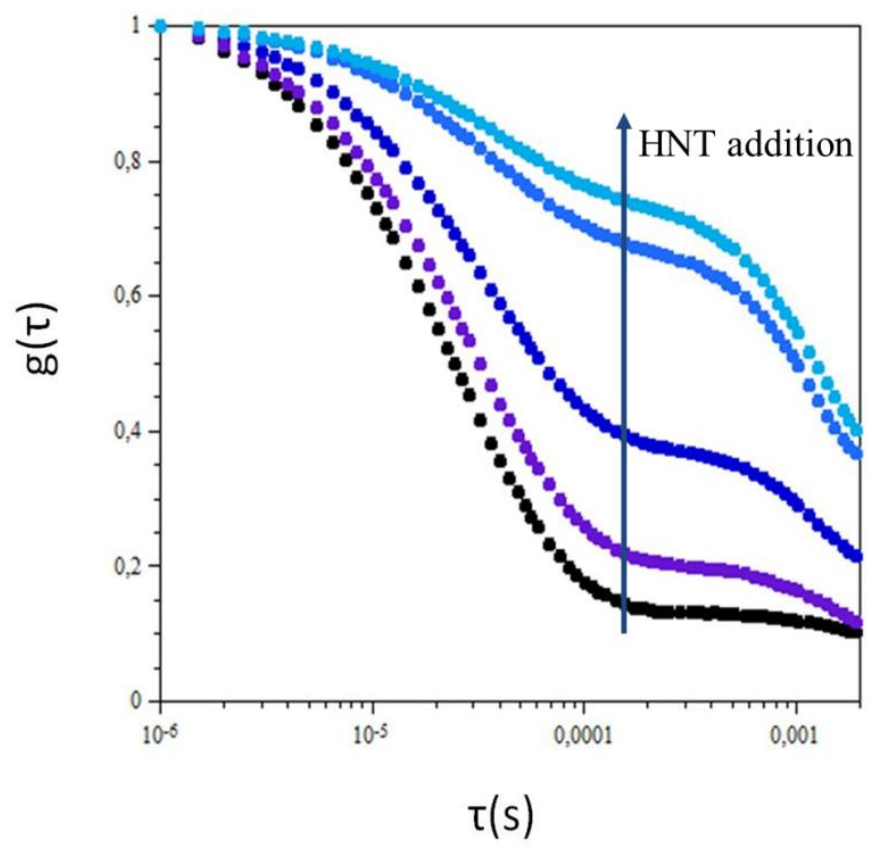

Figure 2. Autocorrelation function for halloysite nanotubes (HNTs) in microemulsion at $0.014 \%(\bullet)$, $0.0125 \%(\bullet), 0.005 \%(\bullet), 0.0025 \%(\bullet)$ e $0.0013 \%(\bullet)$.

The hydrodynamic radii, calculated from the field-time autocorrelation functions, were reported as a function of \% HNT content (Figure 3a). The increase of HNT content in the investigated suspensions appears to have a negligible effect on the Rh of the two particle populations, indicating a type of interaction that does not involve a significant change in particle size. These findings may be correlated to an electrostatic adsorption of negative oil droplets into the positively charged HNT lumen. Furthermore, the $\mathrm{g}(\tau)$ function provides information about the concentration of the dispersed particles (B and C parameters in Equation (1)). Figure $3 \mathrm{~b}$ shows the concentration percentage of the two populations as the HNT content increases. The microemulsion decreases, and the content of nanotubes increases, with a non-linear trend. This behavior suggests that the oil droplets have been partially driven into the halloysite nanocontainer lumen. 


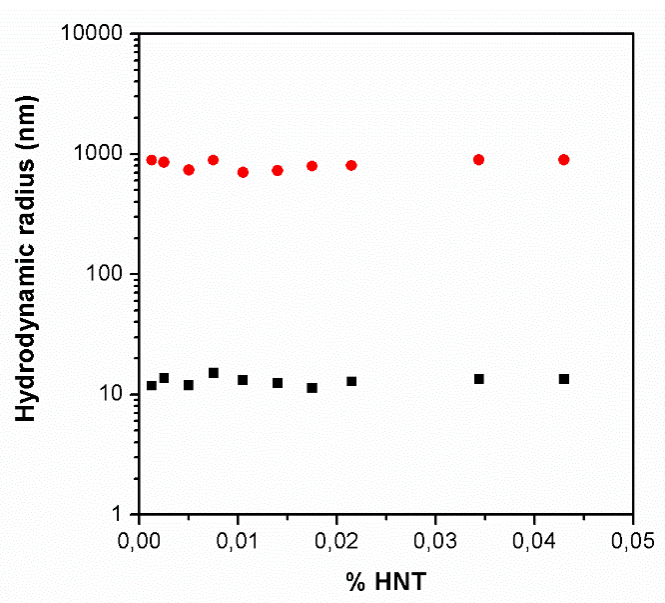

(a)

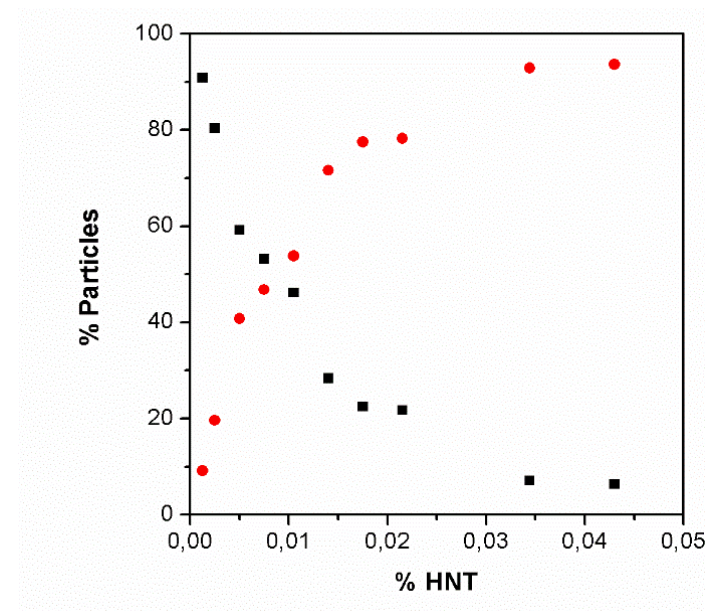

(b)

Figure 3. (a) Hydrodynamic radius of HNT (red circles) and microemulsion (black squares). (b) \% of particles from DLS intensity for microemulsion (black squares) and HNT (red circles) particles.

The oil droplet inclusion into the HNT lumen is shown in Figure 4 and represents the B/C ratio as a function of the SDS/HNT ratio. We observe a linear increase if the interaction between particles, ideally, does not involve any changes in their concentration. On the contrary, it was found that for $\mathrm{R}_{\mathrm{SDS} / \mathrm{HNT}} \leq 915$, as SDS content increases, the B factor increases at a lower rate. This can be explained by considering a possible interaction involving an adsorption of microemulsion into the HNT lumen. In this case, the loaded oil droplets do not scatter, resulting in a slower increase to the $\mathrm{B} / \mathrm{C}$ ratio.

In particular, for $\mathrm{R}_{\mathrm{SDS} / \mathrm{HNT}} \leq 1000(0.02 \%$ of $\mathrm{HNT})$, it is possible to hypothesize the instauration of an equilibrium between micelles dispersed in solution and loaded into the nanotubes. The value of $\mathrm{R}_{\mathrm{SDS} / \mathrm{HNT}}=1000$ can be considered as a parameter for the estimation of the saturation limit. In fact, with a higher amount of SDS, the B/C rises linearly as in absence of any interaction.

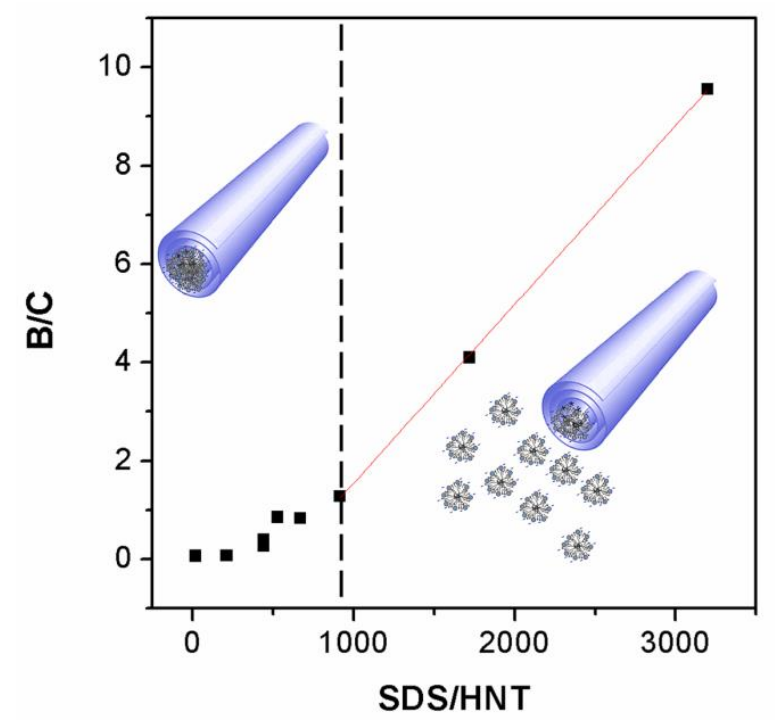

Figure 4. B/C ratio as a function of sodium dodecyl sulphate (SDS)/HNT ratio for the HNT-microemulsion prepared and their schematic representation. 


\subsection{Cleaning Tests on a Marble Sculpture}

The Kilgas are decorative supports for jade, formed by an octagonal trunk of hollow marble. The end of the trunk closes with a solid base that continues through a short pass inclined through a tricuspid bow opening in a protruding frontal basin. Four stylized legs support the octagonal trunk. A jar full of water was placed vertically on the trunk with the water flowing through the porous body of the vessel into the protruding mouth and was collected by using cups.

The exterior of the trunk was decorated with Islamic traditions, such as the muqarnas, which are found in many works in the Palermo area, including the wooden roof muqarnas of the Palatine Chapel.

The first cleaning step had been mechanical, with the use of an aspirator set to low power and a brusher for the removal of superficial deposits. The stone surface was visibly shiny and greasy to the touch. A coherent film was deposited on the marble surface and by means of a Frontier FTIR spectrometer (PerkinElmer, Italy, Milan). analysis shows that the main constituent is an oil-based varnish, likely due to a protective coating applied during a previous restoration.

To achieve fine control of the release of the product onto the stone surface, a membrane of PAN nanofibers was used. The presence of PAN nanofibers ensures the absence of direct contact between the HNTs and the stone surface thus avoiding the release of residues on the surface. Moreover, this protocol guarantees a great control of the cleaning area; the part that has first been treated with a soft bristle brush and rinsed with de-ionized water. A first evaluation of the prepared cleaning system is shown in Figure 5, displaying the treated area before and after cleaning. A second examination of the stone surface, by FT-IR, confirmed the removal of the oily layer from the same work of art (spectra are in Supplementary Materials, Figure S1). Figure 6 shows the full view of the Kilga before and after the cleaning treatment.

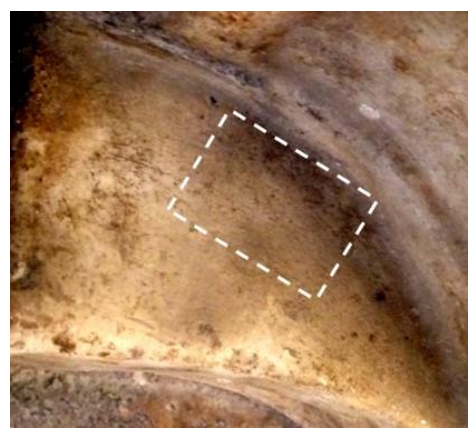

(a)

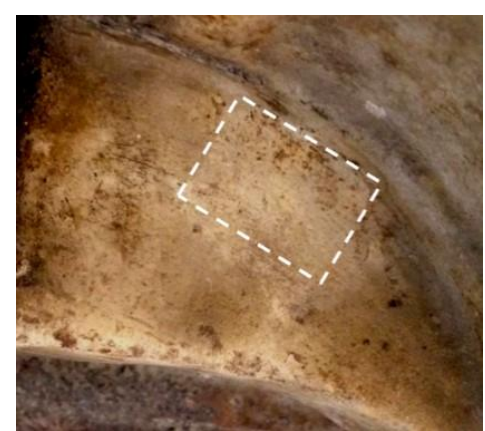

(b)

Figure 5. (a) Marble sculpture before; (b) Marble sculpture after HNT-microemulsion treatment.

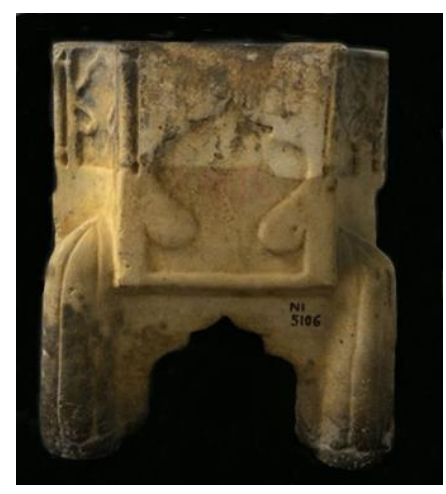

(a)

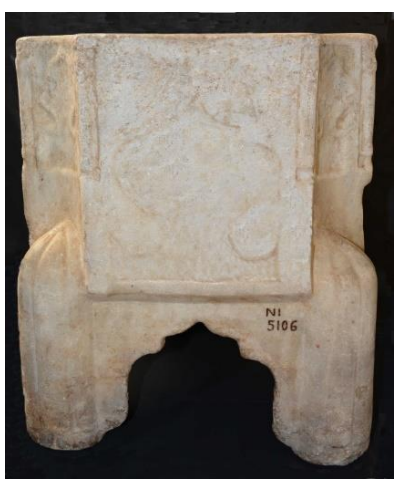

(b)

Figure 6. (a) A full view of the Kilga artifact before; (b) A full view of the Kilga artifact after the cleaning treatment. 


\section{Conclusions}

Colloidal dispersions of HNTs in microemulsion were prepared by mixing components under ultrasonic treatment. The micelles encapsulation was characterized by DLS. The prepared microemulsion showed hydrodynamic radii in the range of $4-22 \mathrm{~nm}$, which was found to be suitable for efficient entrapment into the nanotubes. From the analysis of the autocorrelation function, we have confirmed the presence of surfactant aggregates inside/outside the nanotubes lumen as a function of the nanotubes/surfactant ratio in an aqueous mixture. In particular, an equilibrium between micelles dispersed in solution and loaded into the nanotubes is confirmed up until the saturation limit of $\mathrm{R}_{\mathrm{SDS} / \mathrm{HNT}} \approx 1000$. The application of the prepared emulsion for the controlled cleaning of a marble artifact is demonstrated. To this purpose, a membrane of nanofibrous PAN was prepared by electrospinning and applied between the work of art and the cleaning agent to avoid the release of residues onto the marble surface. The results obtained indicate good cleaning control and efficacy.

Supplementary Materials: The following are available online at http:/ /www.mdpi.com/2076-3417/8/9/1455/s1, Figure S1: FTIR spectra of extracts after first (yellow), second (grey) and third (pink) cleaning cycle. Figure S2: SEM images of Halloysite nanotubes.

Author Contributions: Investigation, G.C., F.S., G.L.D., M.M. and F.P.; Writing and Original Draft Preparation, G.L.D. and F.S.; Review and Editing, G.L., G.C. and P.P.; Supervision, G.L. and P.P.; Validation, G.I.; Funding Acquisition, S.M.

Funding: This research was funded by the University of Palermo.

Conflicts of Interest: The authors declare no conflicts of interest.

\section{References}

1. Baglioni, M.; Giorgi, R.; Berti, D.; Baglioni, P. Smart cleaning of cultural heritage: A new challenge for soft nanoscience. Nanoscale 2012, 4, 42-53. [CrossRef] [PubMed]

2. Baglioni, P.; Chelazzi, D.; Giorgi, R.; Poggi, G. Colloid and materials science for the conservation of cultural heritage: Cleaning, consolidation, and deacidification. Langmuir 2013, 29, 5110-5122. [CrossRef] [PubMed]

3. De Gennes, P.G.; Taupin, C. Microemulsions and the flexibility of oil/water interfaces. J. Phys. Chem. 1982, 86, 2294-2304. [CrossRef]

4. Baglioni, P.; Berti, D.; Bonini, M.; Carretti, E.; Dei, L.; Fratini, E.; Giorgi, R. Micelle, microemulsions, and gels for the conservation of cultural heritage. Adv. Colloid Interface Sci. 2014, 205, 361-371. [CrossRef] [PubMed]

5. Feller, R.L.; Curran, M.; Colaluca, V.; Bogaard, J.; Bailie, C. Photochemical deterioration of poly(vinylbutyral) in the range of wavelengths from middle ultraviolet to the visible. Polym. Degrad. Stab. 2007, 92, 920-931. [CrossRef]

6. Lazzara, G.; Cavallaro, G.; Panchal, A.; Fakhrullin, R.; Stavitskaya, A.; Vinokurov, V.; Lvov, Y. An assembly of organic-inorganic composites using halloysite clay nanotubes. Curr. Opin. Colloid Interface Sci. 2018, 35, 42-50. [CrossRef]

7. Cicala, G.; Tosto, C.; Latteri, A.; La Rosa, A.D.; Blanco, I.; Elsabbagh, A.; Russo, P.; Ziegmann, G. Green composites based on blends of polypropylene with liquid wood reinforced with hemp fibers: Thermomechanical properties and the effect of recycling cycles. Materials 2017, 10, 998. [CrossRef] [PubMed]

8. Kalay, S.; Stetsyshyn, Y.; Lobaz, V.; Harhay, K.; Ohar, H.; Çulha, M. Water-dispersed thermo-responsive boron nitride nanotubes: Synthesis and properties. Nanotechnology 2016, 27, 035703. [CrossRef] [PubMed]

9. Blanco, I.; Bottino, F.A. Thermal study on phenyl, hepta isobutyl-polyhedral oligomeric silsesquioxane/polystyrene nanocomposites. Polym. Compos. 2013, 34, 225-232. [CrossRef]

10. Du, M.; Guo, B.; Jia, D. Thermal stability and flame retardant effects of halloysite nanotubes on poly(propylene). Eur. Polym. J. 2006, 42, 1362-1369. [CrossRef]

11. Du, M.; Guo, B.; Jia, D. Newly emerging applications of halloysite nanotubes: A review. Polym. Int. 2010, 59, 574-582. [CrossRef]

12. Ali, A.; Ahmed, S. A review on chitosan and its nanocomposites in drug delivery. Int. J. Biol. Macromol. 2018, 109, 273-286. [CrossRef] [PubMed] 
13. Darder, M.; López-Blanco, M.; Aranda, P.; Aznar, A.J.; Bravo, J.; Ruiz-Hitzky, E. Microfibrous chitosan-sepiolite nanocomposites. Chem. Mater. 2006, 18, 1602-1610. [CrossRef]

14. Blanco, I. Polysiloxanes in theranostics and drug delivery: A review. Polymers 2018, 10, 755. [CrossRef]

15. Solarski, S.; Mahjoubi, F.; Ferreira, M.; Devaux, E.; Bachelet, P.; Bourbigot, S.; Delobel, R.; Coszach, P.; Murariu, M.; silva Ferreira, A.; et al. (Plasticized) Polylactide/clay nanocomposite textile: Thermal, mechanical, shrinkage and fire properties. J. Mater. Sci. 2007, 42, 5105-5117. [CrossRef]

16. Lisuzzo, L.; Cavallaro, G.; Lazzara, G.; Milioto, S.; Parisi, F.; Stetsyshyn, Y. Stability of halloysite, imogolite, and boron nitride nanotubes in solvent media. Appl. Sci. 2018, 8, 1068. [CrossRef]

17. Yang, Y.; Chen, Y.; Leng, F.; Huang, L.; Wang, Z.; Tian, W. Recent advances on surface modification of halloysite nanotubes for multifunctional applications. Appl. Sci. 2017, 7, 1215. [CrossRef]

18. Joussein, E.; Petit, S.; Churchman, G.J.; Theng, B.; Righi, D.; Delvaux, B. Halloysite clay minerals-A review. Clay Miner. 2005, 40, 383-426. [CrossRef]

19. Joo, Y.; Jeon, Y.; Lee, S.U.; Sim, J.H.; Ryu, J.; Lee, S.; Lee, H.; Sohn, D. Aggregation and Stabilization of Carboxylic Acid Functionalized Halloysite Nanotubes (HNT-COOH). J. Phys. Chem. C 2012, 116, 18230-18235. [CrossRef]

20. Joo, Y.; Sim, J.H.; Jeon, Y.; Lee, S.U.; Sohn, D. Opening and blocking the inner-pores of halloysite. Chem. Commun. 2013, 49, 4519-4521. [CrossRef] [PubMed]

21. Cavallaro, G.; Grillo, I.; Gradzielski, M.; Lazzara, G. Structure of hybrid materials based on halloysite nanotubes filled with anionic surfactants. J. Phys. Chem. C 2016, 120, 13492-13502. [CrossRef]

22. Cavallaro, G.; Chiappisi, L.; Pasbakhsh, P.; Gradzielski, M.; Lazzara, G. A structural comparison of halloysite nanotubes of different origin by Small-Angle Neutron Scattering (SANS) and Electric Birefringence. Appl. Clay Sci. 2018, 160, 71-80. [CrossRef]

23. Fakhrullin, R.F.; Lvov, Y.M. Halloysite clay nanotubes for tissue engineering. Nanomedicine 2016, 11, $2243-2246$. [CrossRef] [PubMed]

24. Kryuchkova, M.; Danilushkina, A.; Lvov, Y.; Fakhrullin, R. Evaluation of toxicity of nanoclays and graphene oxide in vivo: A Paramecium caudatum study. Environ. Sci. Nano 2016, 3, 442-452. [CrossRef]

25. Lvov, Y.M.; DeVilliers, M.M.; Fakhrullin, R.F. The application of halloysite tubule nanoclay in drug delivery. Expert Opin. Drug Deliv. 2016, 13, 977-986. [CrossRef] [PubMed]

26. Wang, X.; Gong, J.; Rong, R.; Gui, Z.; Hu, T.; Xu, X. Halloysite nanotubes-induced Al accumulation and fibrotic response in lung of mice after 30-day repeated oral administration. J. Agric. Food Chem. 2018, 66, 2925-2933. [CrossRef] [PubMed]

27. Levis, S.R.; Deasy, P.B. Characterisation of halloysite for use as a microtubular drug delivery system. Int. J. Pharm. 2002, 243, 125-134. [CrossRef]

28. Shutava, T.G.; Fakhrullin, R.F.; Lvov, Y.M. Spherical and tubule nanocarriers for sustained drug release. Curr. Opin. Pharmacol. 2014, 18, 141-148. [CrossRef] [PubMed]

29. Liu, Y.; Guan, H.; Zhang, J.; Zhao, Y.; Yang, J.-H.; Zhang, B. Polydopamine-coated halloysite nanotubes supported AgPd nanoalloy: An efficient catalyst for hydrolysis of ammonia borane. Int. J. Hydrog. Energy 2018, 43, 2754-2762. [CrossRef]

30. Liu, Y.; Zhang, J.; Guan, H.; Zhao, Y.; Yang, J.-H.; Zhang, B. Preparation of bimetallic Cu-Co nanocatalysts on poly (diallyldimethylammonium chloride) functionalized halloysite nanotubes for hydrolytic dehydrogenation of ammonia borane. Appl. Surf. Sci. 2018, 427, 106-113. [CrossRef]

31. Sadjadi, S.; Hosseinnejad, T.; Malmir, M.; Heravi, M.M. Cu@furfural imine-decorated halloysite as an efficient heterogeneous catalyst for promoting ultrasonic-assisted A3 and KA2 coupling reactions: A combination of experimental and computational study. New J. Chem. 2017, 41, 13935-13951. [CrossRef]

32. Sadjadi, S.; Heravi, M.M.; Malmir, M. Pd@HNTs-CDNS-g-C3N4: A novel heterogeneous catalyst for promoting ligand and copper-free Sonogashira and Heck coupling reactions, benefits from halloysite and cyclodextrin chemistry and g-C3N4 contribution to suppress Pd leaching. Carbohydr. Polym. 2018, 186, $25-34$. [CrossRef] [PubMed]

33. Machado, G.S.; de Freitas Castro, K.A.D.; Wypych, F.; Nakagaki, S. Immobilization of metalloporphyrins into nanotubes of natural halloysite toward selective catalysts for oxidation reactions. J. Mol. Catal. A Chem. 2008, 283, 99-107. [CrossRef] 
34. Hong, M.C.; Ahn, H.; Choi, M.C.; Lee, Y.; Kim, J.; Rhee, H. Pd nanoparticles immobilized on PNIPAM-halloysite: Highly active and reusable catalyst for Suzuki-Miyaura coupling reactions in water. Appl. Organomet. Chem. 2014, 28, 156-161. [CrossRef]

35. Zhao, Y.; Abdullayev, E.; Vasiliev, A.; Lvov, Y. Halloysite nanotubule clay for efficient water purification. J. Colloid Interface Sci. 2013, 406, 121-129. [CrossRef] [PubMed]

36. Cavallaro, G.; Gianguzza, A.; Lazzara, G.; Milioto, S.; Piazzese, D. Alginate gel beads filled with halloysite nanotubes. Appl. Clay Sci. 2013, 72, 132-137. [CrossRef]

37. Owoseni, O.; Nyankson, E.; Zhang, Y.; Adams, S.J.; He, J.; McPherson, G.L.; Bose, A.; Gupta, R.B.; John, V.T. Release of surfactant cargo from interfacially-active halloysite clay nanotubes for oil spill remediation. Langmuir 2014, 30, 13533-13541. [CrossRef] [PubMed]

38. Panchal, A.; Swientoniewski, L.T.; Omarova, M.; Yu, T.; Zhang, D.; Blake, D.A.; John, V.; Lvov, Y.M. Bacterial proliferation on clay nanotube Pickering emulsions for oil spill bioremediation. Colloids Surf. B Biointerfaces 2018, 164, 27-33. [CrossRef] [PubMed]

39. Bertolino, V.; Cavallaro, G.; Lazzara, G.; Merli, M.; Milioto, S.; Parisi, F.; Sciascia, L. Effect of the biopolymer charge and the nanoclay morphology on nanocomposite materials. Ind. Eng. Chem. Res. 2016, 55, 7373-7380. [CrossRef]

40. Liu, M.; Zhang, Y.; Wu, C.; Xiong, S.; Zhou, C. Chitosan/halloysite nanotubes bionanocomposites: Structure, mechanical properties and biocompatibility. Int. J. Biol. Macromol. 2012, 51, 566-575. [CrossRef] [PubMed]

41. Gorrasi, G. Dispersion of halloysite loaded with natural antimicrobials into pectins: Characterization and controlled release analysis. Carbohydr. Polym. 2015, 127, 47-53. [CrossRef] [PubMed]

42. Makaremi, M.; Pasbakhsh, P.; Cavallaro, G.; Lazzara, G.; Aw, Y.K.; Lee, S.M.; Milioto, S. Effect of morphology and size of halloysite nanotubes on functional pectin bionanocomposites for food packaging applications. ACS Appl. Mater. Interfaces 2017, 9, 17476-17488. [CrossRef] [PubMed]

43. Gorrasi, G.; Pantani, R.; Murariu, M.; Dubois, P. PLA/Halloysite nanocomposite films: Water vapor barrier properties and specific key characteristics. Macromol. Mater. Eng. 2014, 299, 104-115. [CrossRef]

44. Lvov, Y.; Wang, W.; Zhang, L.; Fakhrullin, R. Halloysite clay nanotubes for loading and sustained release of functional compounds. Adv. Mater. 2016, 28, 1227-1250. [CrossRef] [PubMed]

45. Grimes, R.W.; Luo, Y.; McFarland, W.A.; Mills, K.D. Bi-functionalized clay nanotubes for anti-cancer therapy. Appl. Sci. 2018, 8, 281. [CrossRef]

46. Cavallaro, G.; Lazzara, G.; Milioto, S.; Parisi, F.; Evtugyn, V.; Rozhina, E.; Fakhrullin, R. Nanohydrogel formation within the halloysite lumen for triggered and sustained release. ACS Appl. Mater. Interfaces 2018, 10, 8265-8273. [CrossRef] [PubMed]

47. Cavallaro, G.; Lazzara, G.; Milioto, S.; Parisi, F. Hydrophobically modified halloysite nanotubes as reverse micelles for water-in-oil emulsion. Langmuir 2015, 31, 7472-7478. [CrossRef] [PubMed]

48. Cavallaro, G.; Lazzara, G.; Milioto, S.; Parisi, F.; Sanzillo, V. Modified halloysite nanotubes: Nanoarchitectures for enhancing the capture of oils from vapor and liquid phases. ACS Appl. Mater. Interfaces 2014, 6, 606-612. [CrossRef] [PubMed]

49. Cavallaro, G.; Lazzara, G.; Konnova, S.; Fakhrullin, R.; Lvov, Y. Composite films of natural clay nanotubes with cellulose and chitosan. Green Mater. 2014, 2, 232-242. [CrossRef]

50. Makaremi, M.; De Silva, R.T.; Pasbakhsh, P. Electrospun nanofibrous membranes of polyacrylonitrile/halloysite with superior water filtration ability. J. Phys. Chem. C 2015, 119, 7949-7958. [CrossRef]

51. Bauduin, P.; Touraud, D.; Kunz, W. Design of low-toxic and temperature-sensitive anionic microemulsions using short propyleneglycol alkyl ethers as cosurfactants. Langmuir 2005, 21, 8138-8145. [CrossRef] [PubMed]

52. Pasbakhsh, P.; Churchman, G.J.; Keeling, J.L. Characterisation of properties of various halloysites relevant to their use as nanotubes and microfibre fillers. Appl. Clay Sci. 2013, 74, 47-57. [CrossRef]

(C) 2018 by the authors. Licensee MDPI, Basel, Switzerland. This article is an open access article distributed under the terms and conditions of the Creative Commons Attribution (CC BY) license (http://creativecommons.org/licenses/by/4.0/). 